\title{
Phase Distribution in the Tip Clearance of a Multiphase Pump at Multiple Operating Points and Its Effect on the Pressure Fluctuation Intensity
}

\author{
Guangtai Shi ${ }^{1}$, Zongku Liu ${ }^{2, *}$, Xiaobing Liu ${ }^{1, *}$, Yexiang Xiao ${ }^{3}$ and Xuelin Tang ${ }^{2}$ \\ 1 Key Laboratory of Fluid and Power Machinery, Ministry of Education, Xihua University, \\ Chengdu 610039, China; shiguangtai_1985@126.com \\ 2 College of Water Resources and Civil Engineering, China Agricultural University, Beijing 100083, China; \\ xl-tang@mail.tsinghua.edu.cn \\ 3 State Key Laboratory of Hydroscience and Engineering, Department of Energy and Power Engineering, \\ Tsinghua University, Beijing 100084, China; xiaoyex@mail.tsinghua.edu.cn \\ * Correspondence: liuzongku@stu.xhu.edu.cn (Z.L.); liuxb@mail.xhu.edu.cn (X.L.); \\ Tel.: +86-183-0285-9383 (Z.L.); +86-139-8203-1333 (X.L.)
}

check for

updates

Citation: Shi, G.; Liu, Z.; Liu, X.; Xiao, Y.; Tang, X. Phase Distribution in the Tip Clearance of a Multiphase Pump at Multiple Operating Points and Its Effect on the Pressure Fluctuation Intensity. Processes 2021, 9, 556. https://doi.org/10.3390/ pr9030556

Academic Editor:

Farhad Ein-Mozaffari

Received: 25 February 2021

Accepted: 18 March 2021

Published: 22 March 2021

Publisher's Note: MDPI stays neutral with regard to jurisdictional claims in published maps and institutional affiliations.

Copyright: (c) 2021 by the authors. Licensee MDPI, Basel, Switzerland. This article is an open access article distributed under the terms and conditions of the Creative Commons Attribution (CC BY) license (https:/ / creativecommons.org/licenses/by/ $4.0 /)$.

\begin{abstract}
Tip clearance has a great effect on the flow and pressure fluctuation characteristics in a multiphase pump, especially at multiple operating points. The phase distribution and pressure fluctuation in tip clearance in a multiphase pump are revealed using the CFD (computational fluid dynamics) technology and high-speed photography methods. In this paper, the phase distribution, the gas-liquid two-phase velocity slip, and the pressure fluctuation intensity are comprehensively analyzed. Results show with the increase of the tip clearance, the multiphase pump pressurization performance is obviously deteriorated. In the meantime, the gas accumulation mainly occurs at the hub, the blade suction side (SS), and the tip clearance, and the maximum gas-liquid two-phase velocity difference is near the impeller streamwise of 0.4 . In addition, the tip clearance improves the gas-liquid two-phase distribution in the pump, that is, the larger the tip clearance is, the more uniform the gas-liquid distribution becomes. Furthermore, the gas leads to the maximum pressure fluctuation intensity in the tip clearance which is closer to the tip leakage flow (TLF) outlet, and has a greater effect on the degree of flow separation in the tip clearance.
\end{abstract}

Keywords: multiphase pump; tip clearance; phase distribution; pressure fluctuation; multiple operating points

\section{Introduction}

With the development of society and the further increase of energy consumption, traditional coal and onshore oil and gas resources are gradually depleted. However, the oil and gas resources in deep sea are abundant. Therefore, oil and gas exploration have shifted from onshore to ocean, especially the development and utilization of oil and gas in deep water area [1,2]. In the meantime, the deep-sea oil and gas resources are usually a mixture of oil, gas, and water, accompanied by some small solid particles, which are the three-phase state in truth. The ratio of oil and gas is often unstable and varies greatly during exploitation. Sometimes the gas void fraction even reaches $100 \%$. If the traditional transportation method is adopted, the oil and gas pipelines are laid separately, and the oil and gas are transported separately by pumps and compressors. At this point, the investment cost is high, the management is difficult, and the economic benefits are low. Based on the above issues, this multiphase transportation technology emerges. The oil and gas mixture are transported by the same pipeline, which optimizes the layout of the oil and gas transportation system, improves economic benefits, and owns broad application prospects [3-5]. 
As the core equipment of the multiphase transportation technology, the multiphase pump is a rotor-powered turbomachine, which is composed of several pressurization units, and each pressurization unit is composed of an impeller and a diffuser [6,7]. In operation of the turbomachine, to avoid friction, a gap must be left between the impeller and shroud, namely the tip clearance [8]. Simultaneously, due to the pressure difference between the blade pressure side (PS) and suction side (SS), the tip leakage flow (TLF) is driven from the PS to SS via the tip clearance. When it flows out of the clearance, it merges with the main flow and forms tip leakage vortex (TLV) [9-11].

Based on the analysis above, many scholars have performed investigations on the tip clearance flow. In terms of experiment, due to the improvement of testing technology and approach, the particle image velocimetry (PIV) and high-speed photography become the crucial research methods for tip clearance flow. Wu et al. [12,13] and Miorini et al. [14] employed PIV and stereoscopic particle image velocimetry (SPIV) technology to investigate the flow characteristics of near blade tip in an axial water-jet pump. Results showed the wall jet contained many vortex structures which became the TLF. Meanwhile, the TLV near the blade tip was entrained and propagated to the adjacent blade PS. Peng et al. [15] adopted the experiment method to observe the tip flow in an elliptical hydrofoil and reveal the TLV formation process. Shen et al. [16] took advantage of the high-speed photography and transient pressure measurements to investigate the TLV, transient flow, and pressure fluctuation characteristics of TLV in the axial flow pump. Results revealed the relationship between the tip cavitation and pressure fluctuation.

Although the experiment method obtains reliable data, due to the large cost and long period, the research on blade tip clearance flow at present is mainly based on numerical simulation. Zhang et al. $[17,18]$ applied computational fluid dynamics (CFD) software ANSYS CFX to inquiry the flow patterns and pressure fluctuation characteristics in the multiphase pump with different tip clearances. It was illustrated that TLV appeared at the leading edge (LE) of blade SS, and the dominant frequency and maximum amplitude of the pressure fluctuation gradually augmented with the increase of the tip clearance. Based on the Reynolds time-averaged Navier-Stokes equations, Shi et al. $[19,20]$ utilized numerical simulation methods to survey the effect of inlet gas void fraction on the TLV, and revealed the TLV trajectory and dynamics characteristics. Zhang et al. [21,22], Shen et al. [23], and Feng et al. [24] made use of CFD software to look into the effect of TLF and tip clearance on pressure fluctuation in an axial flow pump. Results demonstrated that tip flow structure was closely related to the blade tip size and flow rate, and the TLV also induce cavitation. In addition, the tip clearance enhanced the pressure fluctuation strength in the impeller, however, the effect on the pressure fluctuation in the diffuser was not obvious. Based on the finite volume method (FVM), Yu et al. [25] and Zhang et al. [26] applied ANSYS CFX software to probe into the effect of tip clearance on the flow patterns and pressure fluctuation characteristics in a low specific speed mixed flow pump, and pointed out the effect of tip clearance on pump performance at large flow rate was more obvious. In the meantime, the rotor and stator interaction (RSI) was the reason for the pressure fluctuation, and the TLF had less effect on the impeller inlet and middle region within a certain range. In addition, some other scholars applied numerical simulation methods to investigate the TLF in turbomachinery such as centrifugal pumps [27,28], compressors [29,30], fans [31,32].

In brief, the TLF and pressure fluctuation characteristics in both experiment and simulation have already been conducted. The results reveal its internal mechanism. However, in terms of the multiphase pump, the investigations at present rarely involve the TLF problem with the gas-liquid two-phase case. Of course, there are fewer researches involving the comparison between the water and gas-liquid two-phase cases, and the related research is not sufficient. Therefore, taking the multiphase pump as the research object, the phase distribution, TLF, and pressure fluctuation characteristics under the water (Inlet gas void fraction $(\mathrm{IGVF})=0)$ and gas-liquid two-phase $(\mathrm{IGVF}=10 \%)$ cases with different tip clearances (Rtc $=0.5 \mathrm{~mm}, 1.0 \mathrm{~mm}$, and $1.5 \mathrm{~mm}$ ) are investigated in this paper. Results reveal the effect of the flow and pressure fluctuation in the tip clearance. 


\section{Research Object}

To perform the investigation conveniently, a single pressurization unit of the six-stage multiphase pump is selected in this paper. Meanwhile, the impeller inlet and the diffuser outlet are extended to ensure stable flow and reduce the effect of the boundary conditions. The model is shown in Figure 1, and the main design parameters are as follows: design flow $\mathrm{Q}=100 \mathrm{~m}^{3} / \mathrm{h}$, design rotational speed $n=3000 \mathrm{rpm}$, and the impeller and diffuser blades are 3 and 7 , respectively. To conduct the research with different tip clearances, three different tip clearances (Rtc $=0.5 \mathrm{~mm}, 1.0 \mathrm{~mm}$, and $1.5 \mathrm{~mm}$ ) are purposefully designed. The meridian parameters are shown in Figure 2. In Figure 2, the r represents the radial direction of the impeller and diffuser. In the meantime, the $\mathrm{z}$ represents the rotation axis of impeller, and is also the central axis of the diffuser.

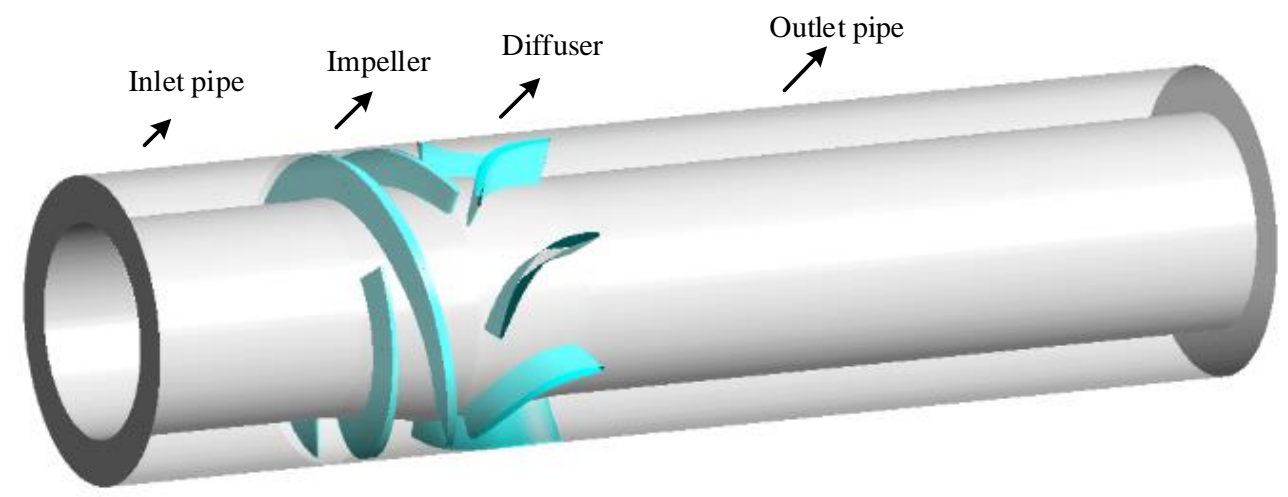

Figure 1. Numerical model.

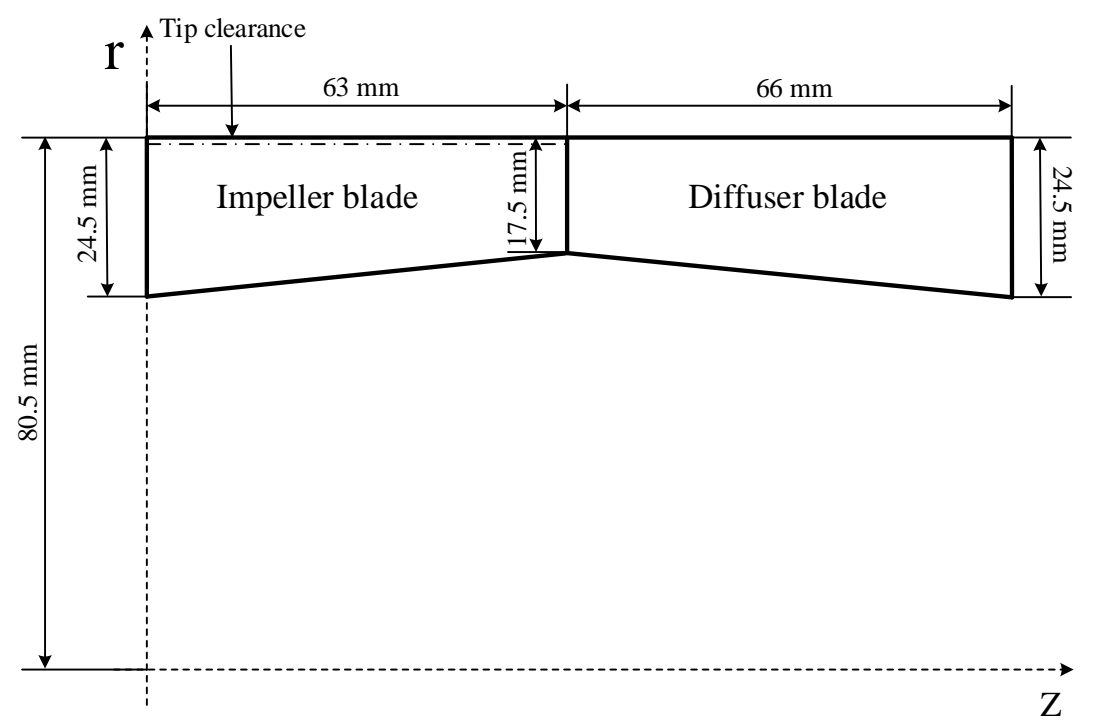

Figure 2. Impeller and diffuser meridian parameters.

\section{Numerical Methods and Settings}

\subsection{Mesh Arrangement}

Mesh quality plays an important role in CFD simulation accuracy. Therefore, highquality hexahedral mesh is used for all computational domains in this paper. The inlet and outlet pipes are divided by ICEM CFD, and the impeller and diffuser are divided by TurboGrid. In the process of mesh arrangement, the near wall, tip clearance, and large curvature region are refined to capture the flow details. The specific mesh is shown in Figure 3. 


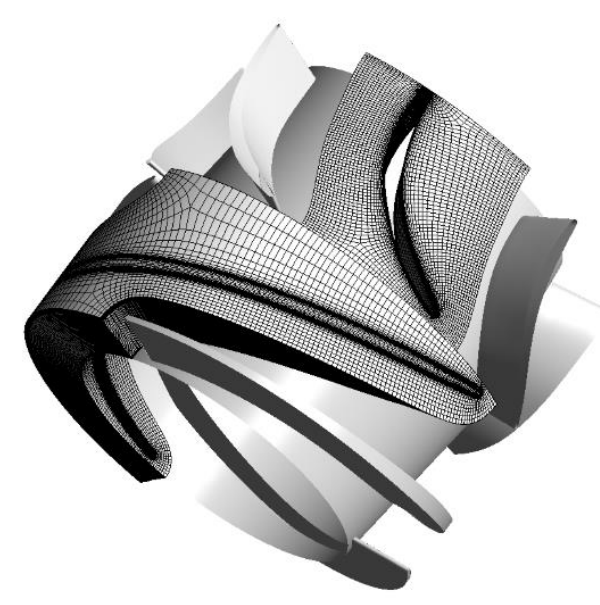

Single passage mesh of impeller and diffuser

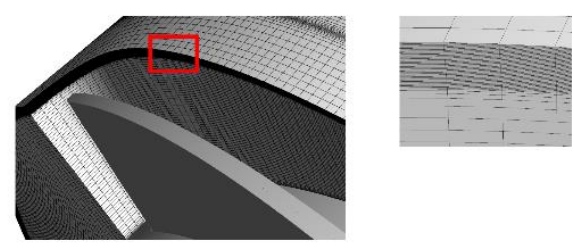

Mesh of tip clearance
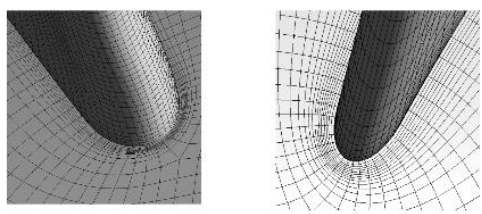

Mesh around blade

Figure 3. Computational mesh.

\subsection{Mesh and Time Step Independence Verification \\ 3.2.1. Mesh Independence Verification}

To reduce the effect of the mesh number on the simulation results, 5 sets of meshes are provided and the simulation in the same operating point is performed. Then, pump head and efficiency are presented in Table 1. From Table 1, when the mesh number exceeds mesh 4 , the effect of mesh number on the simulation results is negligible. After comprehensive consideration, mesh 4 is selected in final numerical simulation.

Table 1. Mesh independence verification.

\begin{tabular}{cccccc}
\hline Parameters & Mesh 1 & Mesh 2 & Mesh 3 & Mesh 4 & Mesh 5 \\
\hline Mesh number & $2,490,070$ & $2,921,104$ & $3,251,592$ & $3,676,610$ & $4,726,647$ \\
Head & 6.628 & 6.771 & 6.747 & 6.750 & 6.831 \\
Efficiency & $35.88 \%$ & $37.09 \%$ & $37.14 \%$ & $37.22 \%$ & $37.83 \%$ \\
Head/Head 1 & 1 & 1.0215 & 1.0179 & 1.0183 & 1.0306 \\
Efficiency/Efficiency 1 & 1 & 1.0337 & 1.0349 & 1.0373 & 1.0542 \\
\hline
\end{tabular}

\subsubsection{Time Step Independence Verification}

To accurately capture the unsteady flow field information, the time step independence is verified. In this verification case, the time steps are set as $5.56 \times 10^{-5} \mathrm{~s}, 1.11 \times 10^{-4} \mathrm{~s}$, $1.67 \times 10^{-4} \mathrm{~s}$, which are the impeller rotation times of $1^{\circ}, 2^{\circ}$, and $3^{\circ}$. The time history information of pressure fluctuation on PS near blade tip at impeller outlet and diffuser inlet are extracted and shown in Figure 4. For Figure 4, pressure time histories with three time steps are basically the same, which shows the effect of different time steps on the numerical results is ignored. Considering comprehensively for the simulation time and accuracy, $1.11 \times 10^{-4} \mathrm{~s}$ is finally selected. 


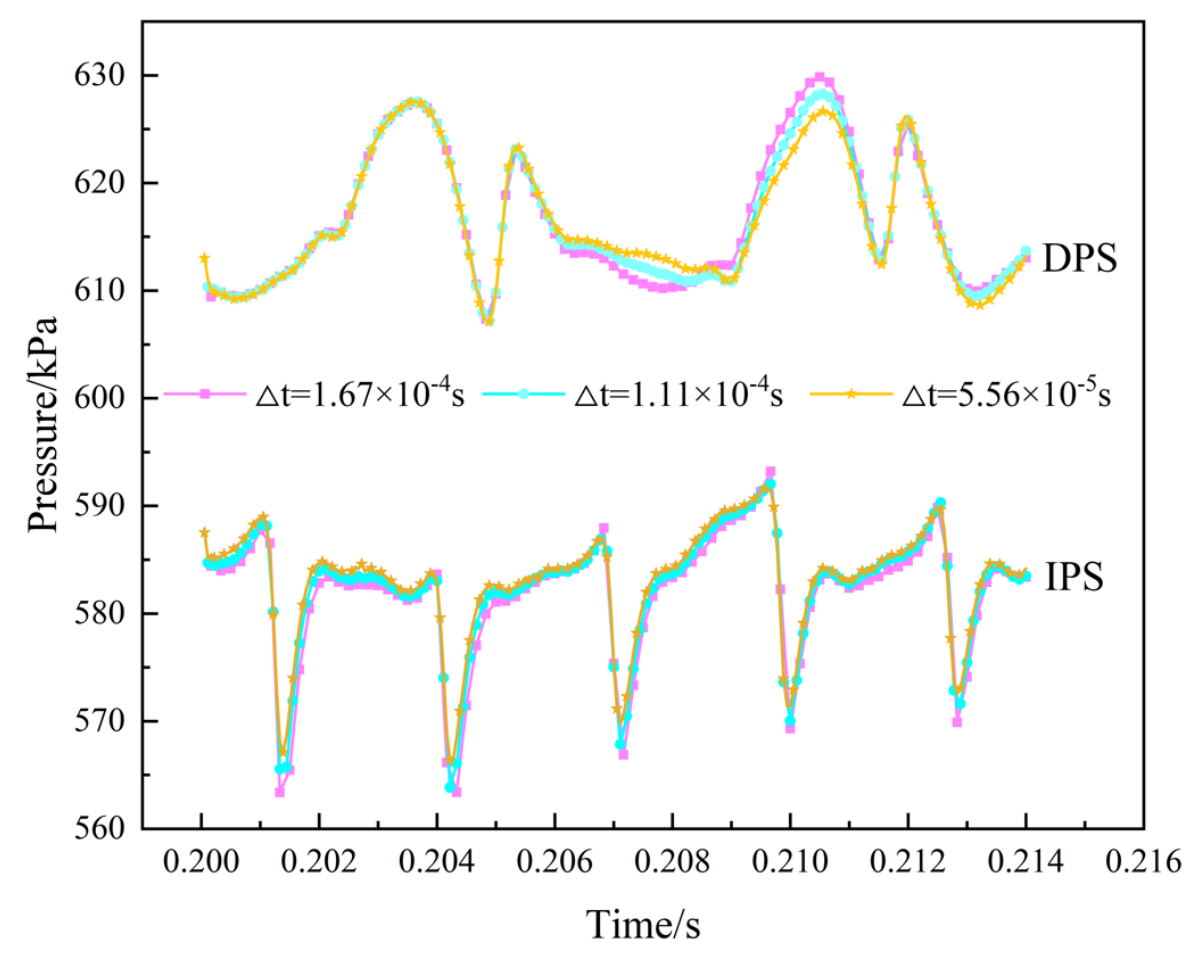

Figure 4. Time step independence verification.

\subsection{Boundary Conditions and Settings}

Based on the Reynolds time-averaged Navier-Stokes (N-S) equations, the CFD software ANSYS CFX is applied to simulate the three-dimensional flow in the multiphase pump under multiple operation points. The boundary conditions and settings are as follows: the velocity and pressure are set for the inlet and outlet, respectively. The impeller wall, diffuser wall and other wall boundaries are set as non-slip wall. The turbulence model adopts SST $k-\omega$, and the residual is set to $10^{-5}$. The interface between the stator and rotor in the pump is set to "Frozen rotor" and "Transient Rotor Stator" in the steady and transient simulations, respectively. In addition, to accelerate the convergence, the steady results are set as the initial value for the transient simulation. The transient simulation is performed for 16 cycles, and the last 6 cycles are selected for analysis.

\subsection{Numerical Method Verification}

The experiment rig is at the Key Laboratory of the Department of Fluid and Power Machinery of Xihua University, as shown in Figure 5. The multiphase pump test system is composed of a multiphase pump, motor, gas-liquid mixing tank, cooling system, lubrication system, control system, gas supply system, water supply system, pipelines, and valves. In the experiment, the multiphase pump with transparent glass component is installed, and the high-speed photography is also employed to capture the flow field near the blade tip, as shown in Figure 6. The camera (RDT16-4G) speed is $500 \mathrm{fps}$, and the resolution is $1280 \times 1024$ pixels. When the resolution is reduced, the maximum speed is $16,000 \mathrm{fps}$. The photography has 4 GB memory, which stores more than 3000 high-resolution images. The shape of the transparent glass is square outside and circle inside to reduce the test error caused by secondary refraction. The water is used for the liquid phase and air is used for the gas phase. In the process of experiment, the gas flow rate is unchanged and adjusting the liquid flow rate is employed to adjust the IGVF. When the experiment system runs stably, high-speed photography is started to photograph the flow details near the blade tip to verify the numerical simulation reliability. 


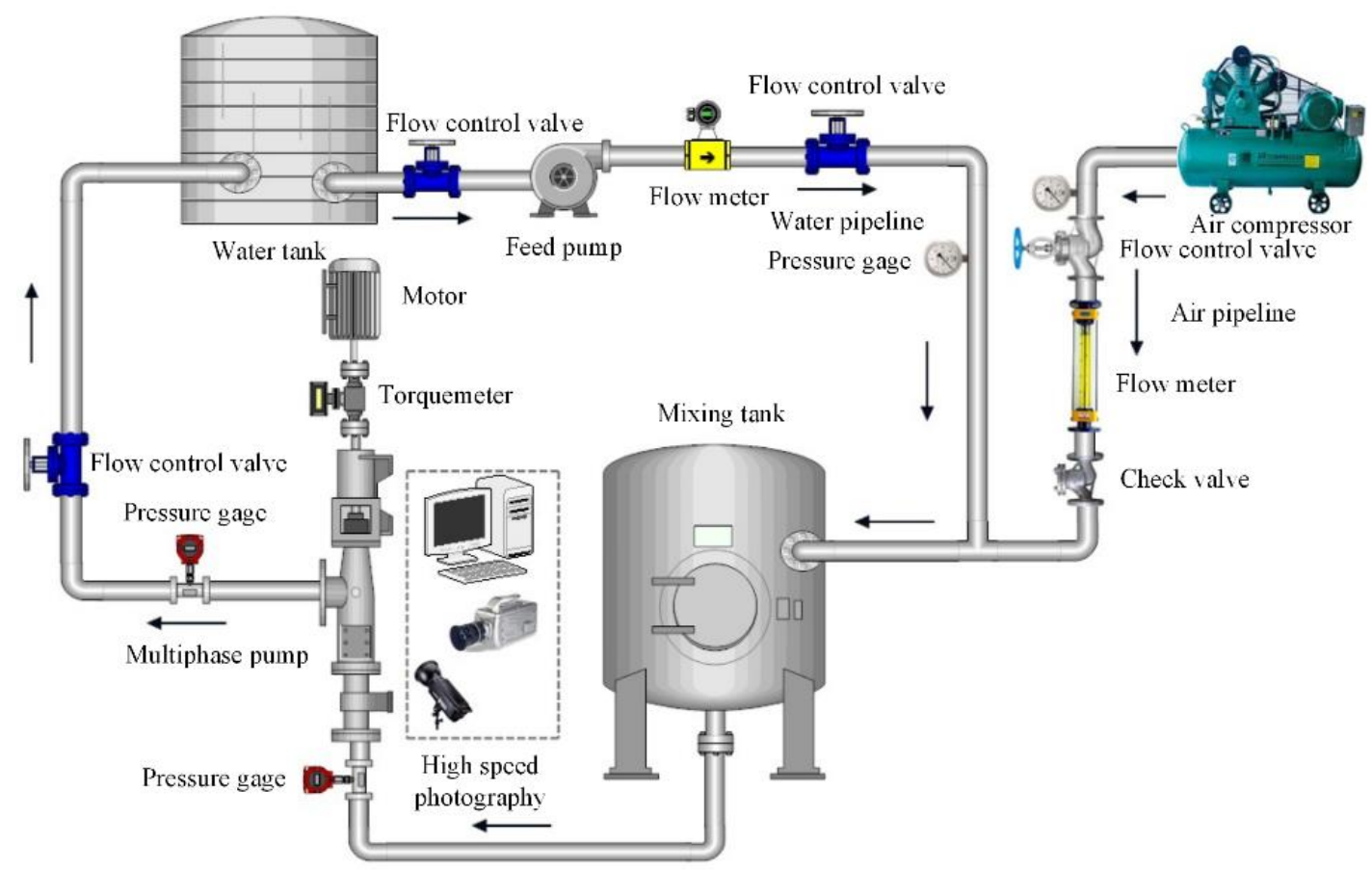

Figure 5. Multiphase pump test system.

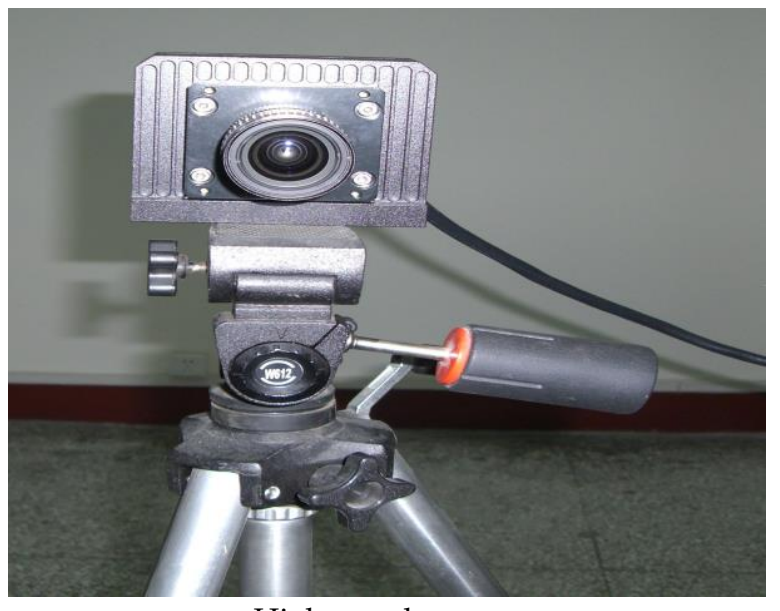

High speed camera

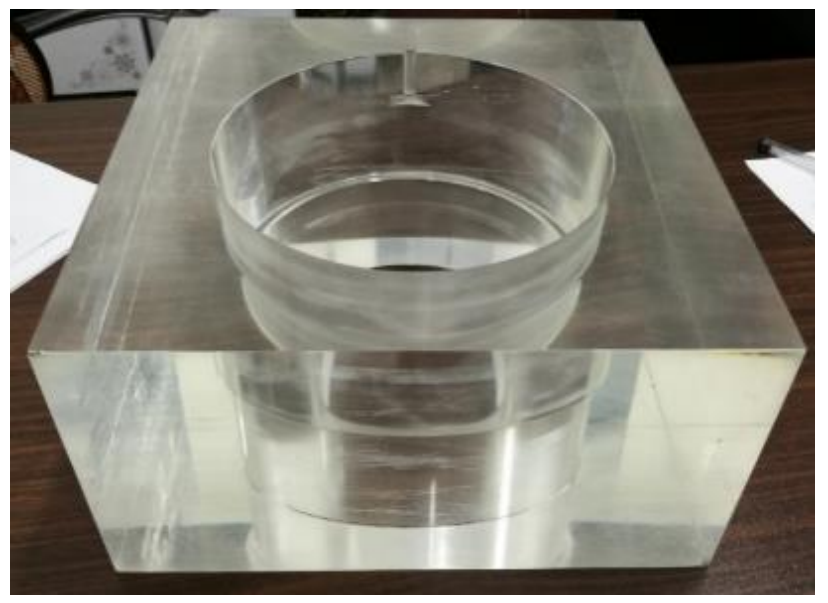

Transparent glass component

Figure 6. High speed camera and transparent glass component.

Figure 7 shows the experimental and CFD flow patterns. For Figure 7, the flow patterns at blade tip in experiment and simulation are labelled in the same color. The experimental flow pattern near the blade tip is in good agreement with the CFD's, especially in water case, which shows the numerical method is reliable. 

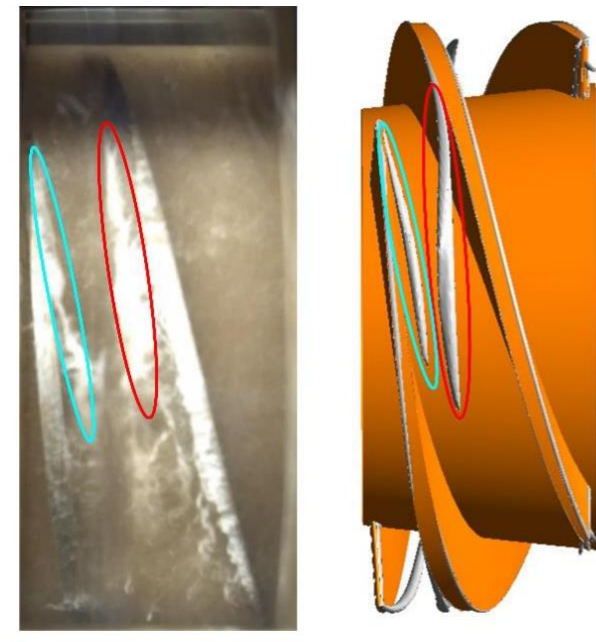

$\mathrm{IGVF}=0$
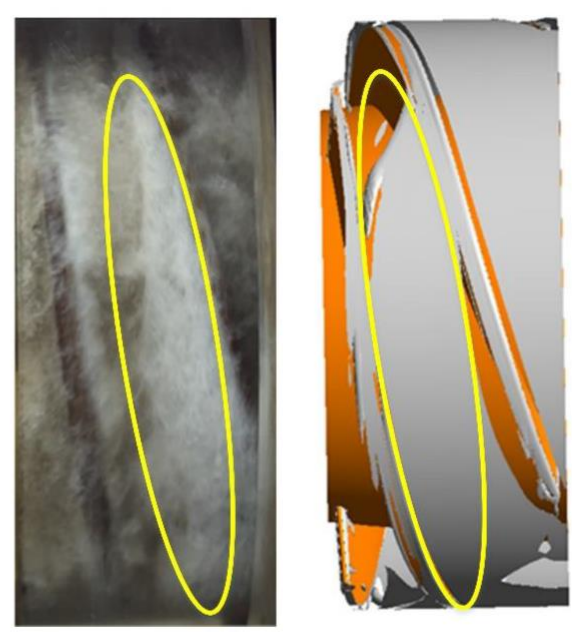

$\mathrm{IGVF}=10 \%$

Figure 7. Experimental and computational fluid dynamic (CFD) flow patterns.

\section{Result and Discussion}

\subsection{Multiphase Pump Pressurization Performance}

Figure 8 presents the multiphase pump pressurization performance at different flow rates. From Figure 8, the tip clearance size has a greater impact on the multiphase pump pressurization performance, and as the tip clearance increases, the pump pressurization performance decreases rapidly. Meanwhile, the IGVF also reduces the pressurization performance, and the effect of the IGVF on the pressurization performance varies with the tip clearance size. When Rtc $=0.5 \mathrm{~mm}$, the IGVF has the greatest impact on the pressurization performance, which decreases most obviously. Meanwhile, the pressurization performance drops more when the flow rate exceeds 1.1 Q. When Rtc $=1.0$ and $1.5 \mathrm{~mm}$, the effects of the IGVF on the pressurization performance are more obvious after exceeding $1.0 \mathrm{Q}$ and $0.9 \mathrm{Q}$, respectively. However, the effect of the IGVF on the pressurization performance is small at other flow rates. In the operation of the multiphase pump, several factors such as tip clearance, flow rate, and IGVF affect the pressurization performance. To keep the pump pressurization ability better, these three factors are emphatically considered in design, optimization, and operation cases.

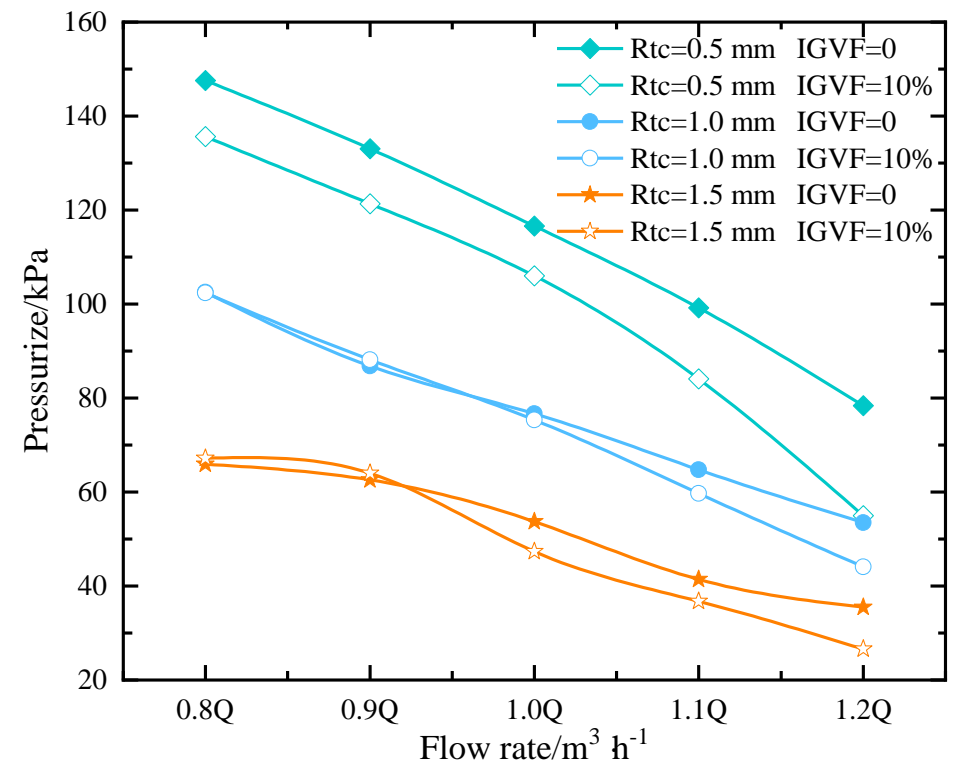

Figure 8. Multiphase pump pressurization performance. 


\subsection{Gas Distribution in the Multiphase Pump Pressurization Unit}

Figure 9 displays the gas distribution in the impeller with different tip clearances at IGVF $=10 \%$ and the isosurface with IGVF $=30 \%$ is selected for display. Meanwhile, Figure 10 shows the three sections in impeller, and Figure 11 illustrates the gas distribution on the different sections. Combining Figures 9 and 11, the three-dimensional (3D) gas distribution in impeller is preferably revealed as follows. The gas in the impeller accumulates in different degrees under different tip clearances, and the accumulation phenomenon mainly occurs at the hub, blade SS, and tip clearance. With the increase of the tip clearance, the gas accumulation on the SS near the trailing edge (TE) becomes more and more serious. In the meantime, the gas accumulation phenomenon occurs near the impeller inlet when the tip clearance Rtc $=1.5 \mathrm{~mm}$. In the process of gas-liquid two-phase transportation, the main cause of gas accumulation is the physical properties of the gas and liquid phases, especially the large difference in density. Because of its low density, the centrifugal force on gas is less, and the gas is pushed to the hub by the liquid. In addition, a small amount of gas accumulation occurs on the PS near the impeller inlet.

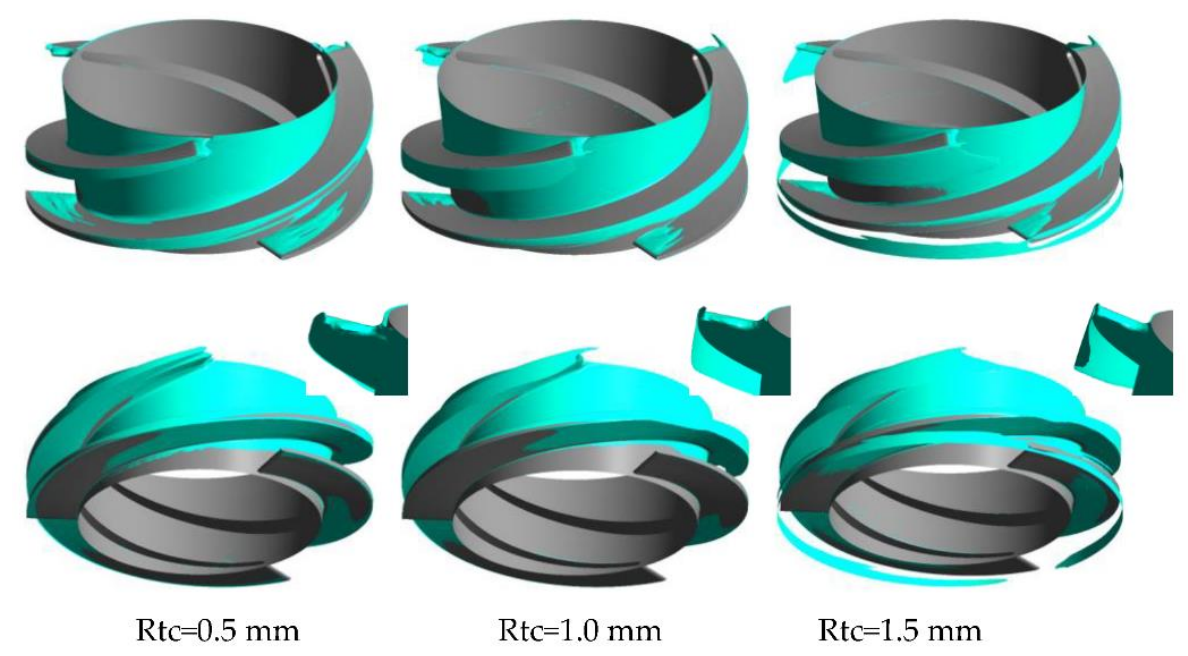

Figure 9. Gas distribution in the impeller at IGVF $=10 \%$.

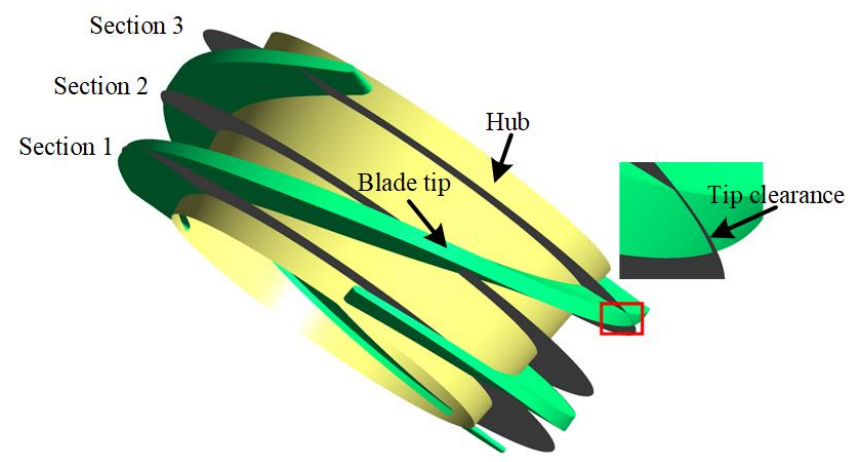

Figure 10. Sections in impeller.

Figure 12 demonstrates the gas distribution in the meridian plane of the pressurization unit under different tip clearances. From Figure 12, when the tip clearance Rtc $=0.5 \mathrm{~mm}$, the gas accumulation mainly occurs near the diffuser hub. However, the gas accumulation near the impeller shroud is less. With the increase of the tip clearance, the gas accumulation phenomenon in the impeller is improved, the gas-liquid two-phase distribution gradually becomes uniform, and the gas-liquid two-phase distribution in the diffuser is also improved, especially at the hub near the rotor stator interface. In general, the tip clearance size has a greater effect on the gas-liquid two-phase distribution in the multiphase pump. The larger 
the tip clearance is, the more uniform the gas-liquid distribution in the multiphase pump becomes. However, an excessively large tip clearance increases hydraulic loss. Therefore, it is necessary to weigh the phase distribution and hydraulic loss to determine the optimal tip clearance.

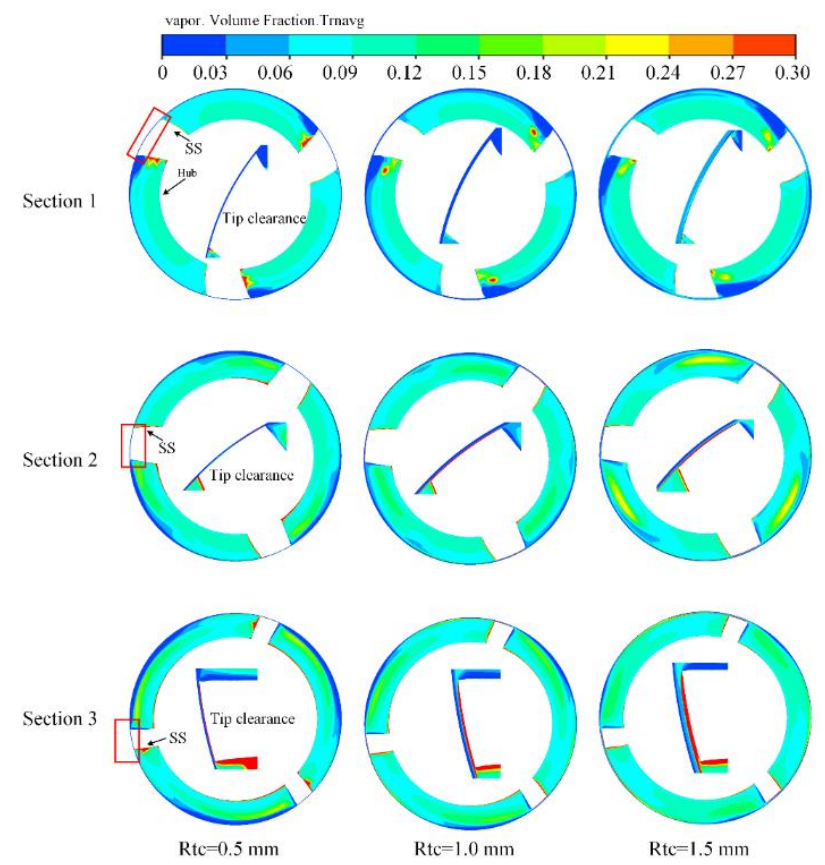

Figure 11. Gas distribution on different sections.

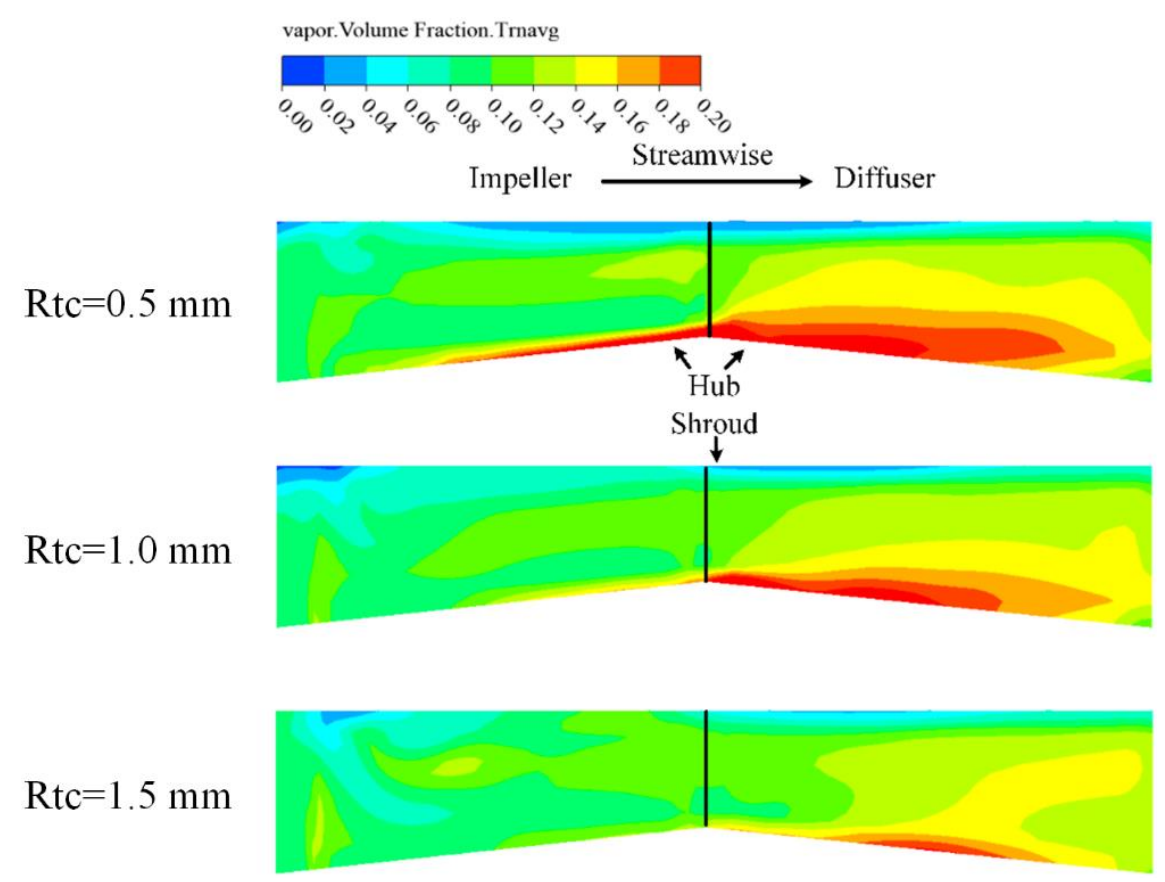

Figure 12. Gas distribution in the impeller and diffuser meridian plane.

To further reveal the gas flow patterns near the blade tip, a line is specially set near the blade tip (In Figure 13), and the three-dimensional gas streamlines are released here to uncover the gas flow law, as shown in Figure 14. For Figure 14, with the increase of the tip clearance, the initial point of the gas streamline gradually moves along the blade profile to the blade TE, and the leakage separation angle (Angle between the TLV and the 
blade profile) suddenly becomes smaller at the Rtc $=1.5 \mathrm{~mm}$ case. In addition, when the tip clearance is small (Rtc $=0.5 \mathrm{~mm}$ ), the gas near the blade tip is less, so the TLF and TLV are not obvious. With the increase of the tip clearance (Rtc $=1.0 \mathrm{~mm}$ ), the TLF increases significantly, and the TLF and the main flow are entrained in the flow passage. Then, the TLV is formed and moved downstream in the flow passage. When the tip clearance increases to $1.5 \mathrm{~mm}$, a small amount of streamlines near the blade leading edge (LE) deflect to the blade PS, and most of the remaining streamlines are entrained as TLV and extend downstream on the blade SS side. Furthermore, the TLV velocity is small when it is first formed, and gradually increased, and finally decreased. This is related to the blade load distribution on the PS and SS.

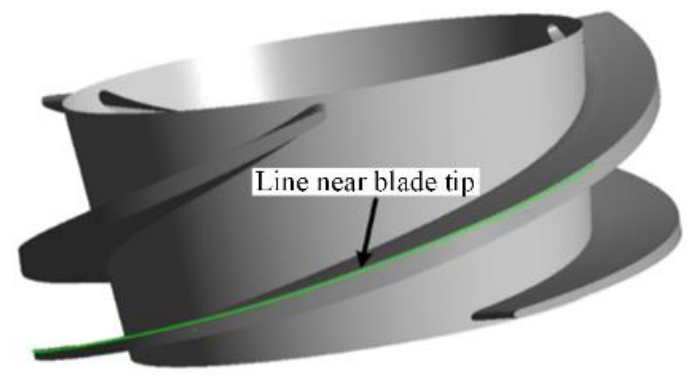

Figure 13. Line near blade tip.

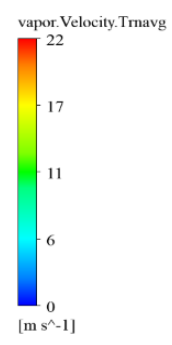

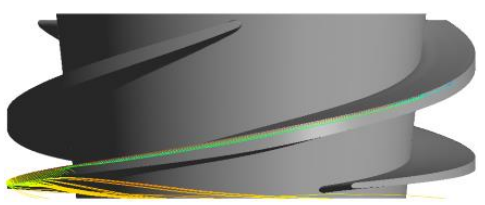

Rtc $=0.5 \mathrm{~mm}$

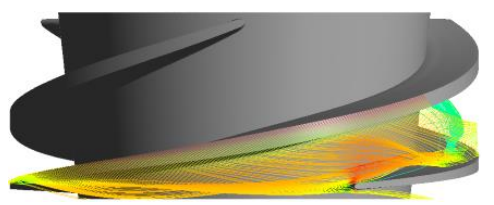

Rtc $=1.0 \mathrm{~mm}$

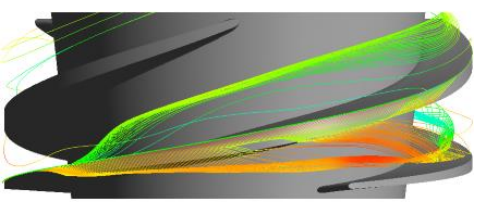

Rtc $=1.5 \mathrm{~mm}$

Figure 14. Gas streamlines near impeller blade tip.

\subsection{Gas-Liquid Two-Phase Velocity Slip in the Pressurization Unit}

Figure 15 is the velocity difference between the gas and liquid along the streamwise in the pressurization unit with different tip clearances. To facilitate the analysis, 0,1 , and 2 are employed to represent the impeller inlet, rotor, and stator interface and diffuser outlet, respectively. The velocity difference between gas and liquid is defined as follows.

$$
\Delta v=v_{g}-v_{l}
$$

where $\Delta v$ denotes the velocity different between gas and liquid. $\mathrm{m} / \mathrm{s} . v_{g}$ and $v_{l}$ denote the gas velocity and liquid velocity, respectively. $\mathrm{m} / \mathrm{s}$.

For Figure 15, the velocity difference between the gas and liquid in impeller is large, and in the diffuser it is basically the same. This is because the impeller is the main energy conversion component, and the gas-liquid two-phase medium needs to complete the energy conversion. The velocity and pressure are changed greatly. However, the diffuser is the rectification component, and the pressure variation is relatively small. In addition, the gas velocity is greater than the liquid velocity at the impeller inlet, rotor, and stator interface and diffuser outlet. However, the gas velocity is less than the liquid velocity at the other locations. The gas is more susceptible to disturbance, so its velocity is greater than that of the liquid. The liquid velocity in the impeller increases gradually along the streamwise, and the velocity difference between gas and liquid reaches the maximum at streamwise of 0.4 , and then begins to gradually decrease. The gas velocity is slightly greater than the 
liquid velocity near the rotor and stator interface. The trend of the gas-liquid two-phase velocity difference under different tip clearances is basically the same. However, with increase of the tip clearance, the minimum value of the velocity difference between the gas and liquid is gradually decreased. In the diffuser, except for the drastic variation of the velocity difference between the gas and liquid at the diffuser inlet in the tip clearance Rtc $=$ $1.5 \mathrm{~mm}$ case, the trend of the gas-liquid velocity difference under different tip clearances is basically the same at other locations. The gas-liquid velocity difference first decreases, then increases, and finally begins to decrease at the diffuser outlet. Through the analysis above, to enhance the gas-liquid two-phase transportation capacity of the multiphase pump, the impeller is especially optimized to prevent the gas-liquid separation phenomenon.

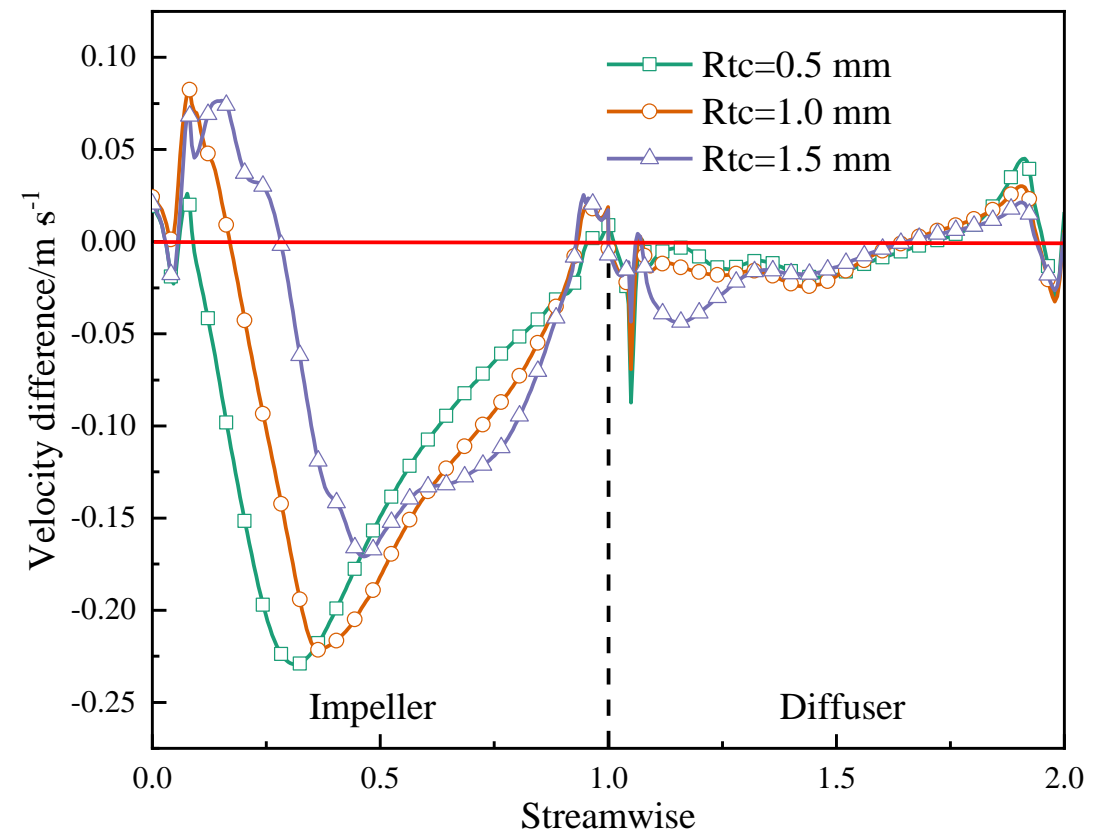

Figure 15. Gas-liquid velocity difference in impeller and diffuser along streamwise.

\subsection{Pressure Fluctuation Intensity in the Tip Clearance}

To quantitatively analyze the variation of pressure fluctuation, the pressure fluctuation intensity and pressure fluctuation coefficient are defined as follows:

$$
\begin{gathered}
\bar{p}=\frac{1}{N} \sum_{i=1}^{N} p_{i} \\
\overline{p^{\prime}}=\sqrt{\frac{1}{N} \sum_{i=1}^{N}\left(p_{i}-\bar{p}\right)^{2}}
\end{gathered}
$$

where $N$ stands for the number of the sample points in the statistical period, $p_{i}$ stands for the pressure at each time step, $\bar{p}$ denotes the arithmetic average value in the statistical period. To conveniently contrast, it is nondimensionalized as follows:

$$
\begin{aligned}
& I_{\mathrm{pf}}=\frac{\overline{p^{\prime}}}{\frac{1}{2} \rho U_{t i p}^{2}} \\
& C_{\mathrm{p}}=\frac{p_{i}-\bar{p}}{\frac{1}{2} \rho U_{t i p}^{2}}
\end{aligned}
$$

where $U_{\text {tip }}$ stands for the circumferential velocity near blade tip at Rtc $=1.0 \mathrm{~mm}$, the value is $24.96 \mathrm{~m} / \mathrm{s}$, and $\rho$ stands for the water density. 
TLF flows through the tip clearance and deteriorates the flow stability and increases the pressure fluctuation intensity. To further analyze the effect of the TLF on the pressure fluctuation intensity, a series sections near the impeller blade tip are set, as shown in Figure 16. The effect of the TLF on the pressure fluctuation intensity is investigated by analyzing the pressure fluctuation intensity on each section. Figure 17 demonstrates the pressure fluctuation intensity and liquid velocity vector on each section from the starting point of the TLV to the blade TE under water (IGVF $=0)$ and gas-liquid two-phase $(\mathrm{IGVF}=10 \%)$ cases when the tip clearance Rtc $=1.5 \mathrm{~mm}$. In Figure 17, at the beginning of the TLV formation, when the TLF enters the tip clearance, a tip separation vortex (TSV) is formed near the blade tip, and the TSV range is larger with gas-liquid two-phase case than that in water case. In the meantime, the larger pressure fluctuation with water case is near the TLF inlet. However, in the gas-liquid two-phase case, it is slightly before the TLF inlet. As the flow flows toward the blade TE, the TSVs are both enhanced under water and gas-liquid two-phase cases. In addition, the larger pressure fluctuation intensity range with water case is expanded near the TLF inlet. However, the larger pressure fluctuation intensity with gas-liquid two-phase case moves forward, and its range is also increased. At section TC3, the maximum pressure fluctuation intensity with water case slightly decreases, and its range is reduced. However, the maximum pressure fluctuation intensity with gas-liquid two-phase case sharply decreases, and the flow separation penetrates the entire tip clearance. In the water case, as the fluid flows to the TE, the flow separation is gradually increased. Meanwhile, the pressure fluctuation intensity is gradually decreased. The pressure fluctuation intensity near the TLF inlet is relatively low, and its range is gradually expanded. In gas-liquid two-phase case, the pressure fluctuation intensity in the tip clearance gradually increases, and near the TLF inlet it also increases slightly. In general, the presence of gas mainly affects the degree of flow separation and the range of the pressure fluctuation intensity in the tip clearance.

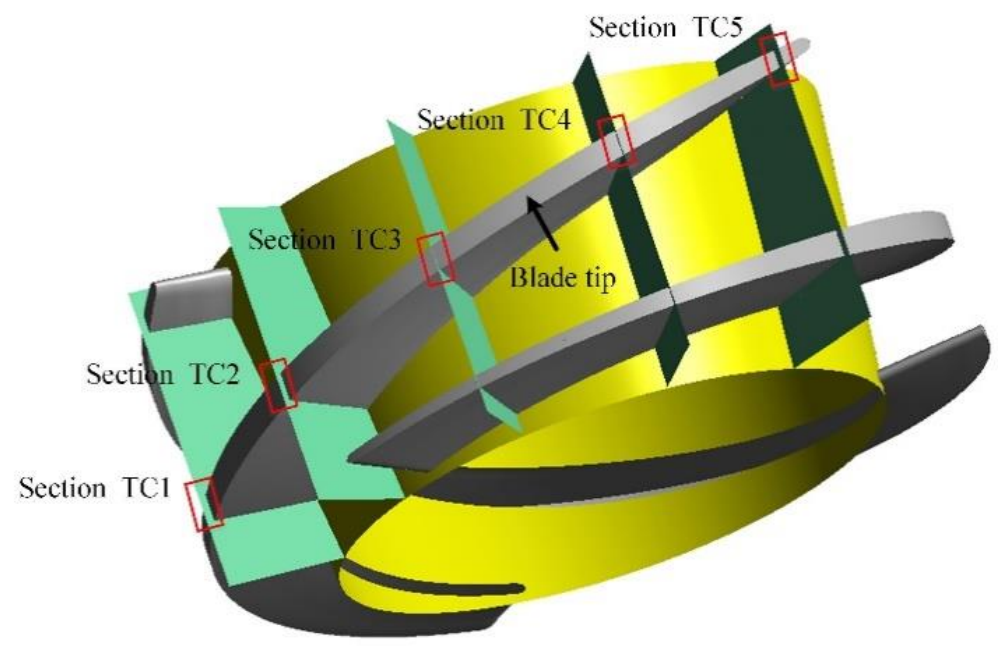

Figure 16. Sections near the impeller blade tip. 
$\mathrm{I}_{\mathrm{pf}}$

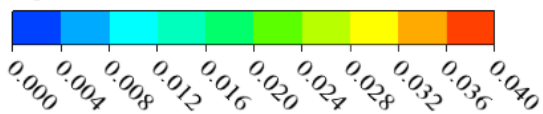

$\mathrm{IGVF}=0$

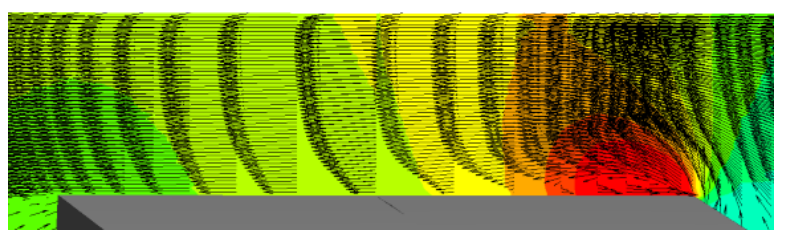

Section TC1
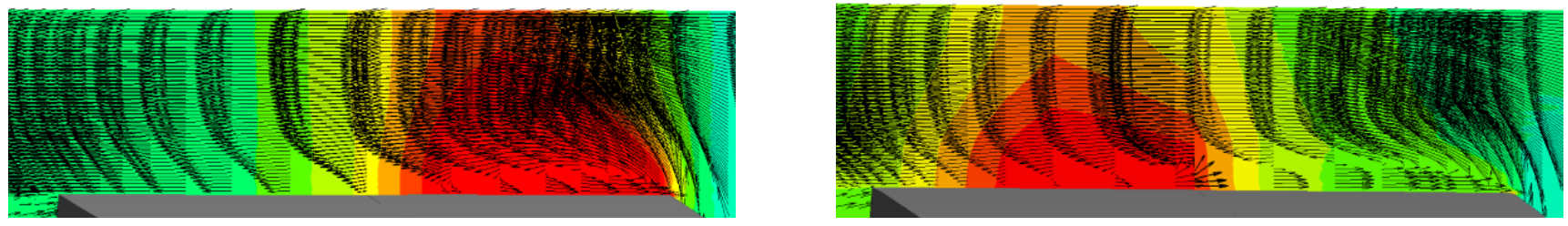

Section TC2
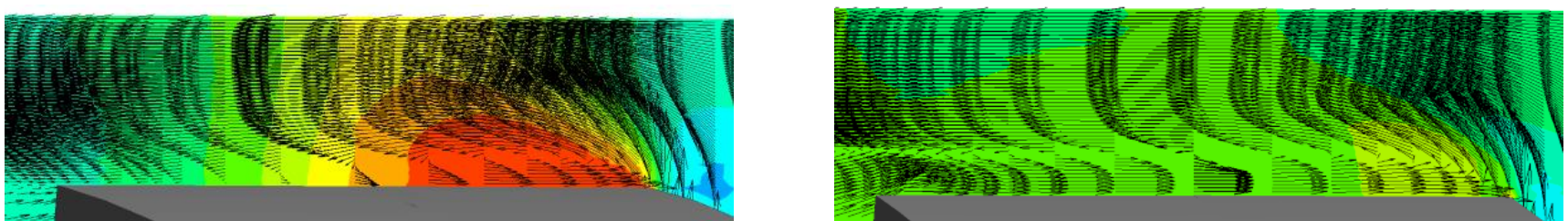

Section TC3
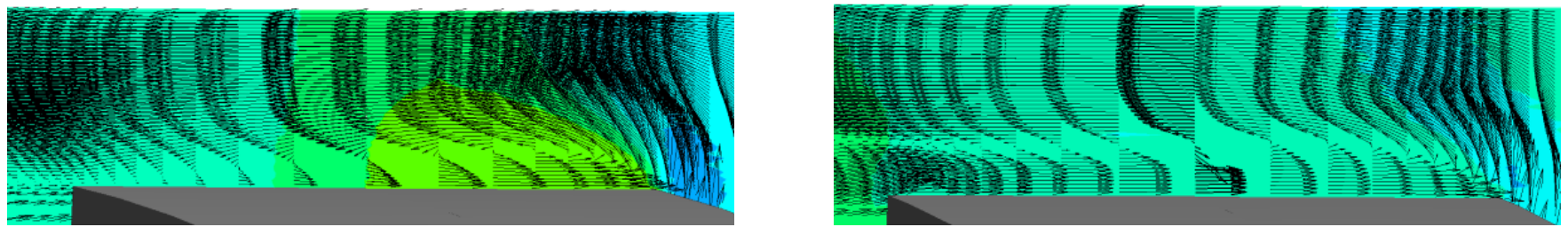

Section TC4
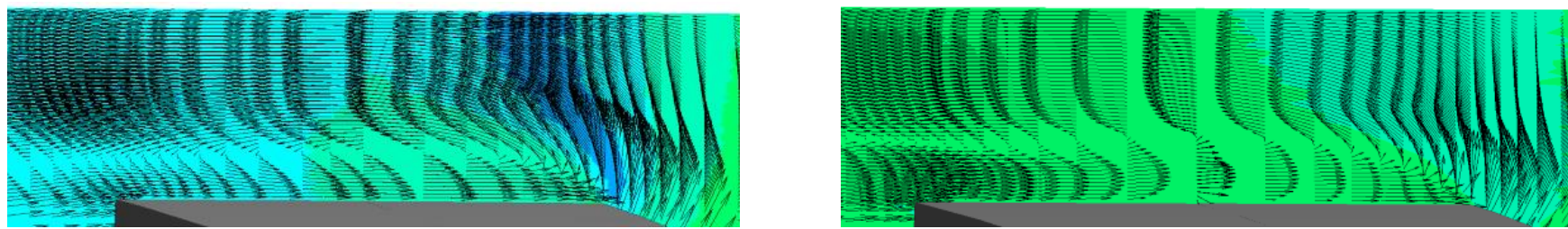

Section TC5

Figure 17. Pressure fluctuation intensity and liquid velocity vector in tip clearance.

\section{Conclusions}

1. As the tip clearance increases, the pump pressurization performance decreases rapidly. Meanwhile, when Rtc $=0.5 \mathrm{~mm}$, the increase of the IGVF reduces the pump pressurization performance at all simulated operating points. However, when Rtc $=1.0$ and $1.5 \mathrm{~mm}$, the increase of the IGVF obviously reduces the pump pressurization performance only at large flow rate. In addition, the gas accumulation in the pump mainly occurs at the hub, blade SS, and tip clearance. Meanwhile, as the tip clearance increases, the gas accumulation in the tip clearance near the impeller blade TE becomes more serious, and the starting point of the gas TLV gradually moves backward.

2. Under different tip clearances, the velocity difference between the gas and liquid in the impeller is relatively large. However, in the diffuser it is relatively small. The maximum velocity difference between the gas and liquid is mainly near the 
impeller streamwise of 0.4 . In the meantime, the tip clearance improves the gasliquid two-phase distribution in the pump, that is, the larger the tip clearance is, the more uniform the gas-liquid two-phase in the pump becomes. However, an excessively large clearance increases hydraulic loss, so the optimal tip clearance needs comprehensive weight.

3. The gas leads the maximum pressure fluctuation intensity in the tip clearance closer to the TLF outlet, and the flow separation also penetrates the entire tip clearance in advance. In addition, the flow separation degree in the tip clearance is largely affected by the gas.

Author Contributions: G.S.: software. Z.L.: writing—original draft, software, writing-review and editing. X.L.: conceptualization. Y.X.: supervision, conceptualization. X.T.: conceptualization, software. All authors have read and agreed to the published version of the manuscript.

Funding: This work was supported by the National Key Research and Development Program (2018YFB0905200), Open Research Fund Program of State key Laboratory of Hydroscience and Engineering (sklhse-2021-E-03), Education department key project of Sichuan province of China (Grant No. 17ZA0366), the Key scientific research fund of Xihua University of China (Grant No.Z1510417), Open Research Subject of Key Laboratory of Fluid and Power Machinery, Ministry of Education (Grant No. LTDL2020-008), the National Natural Science Foundation of China (Grant Nos. 52079140, 51479093), the National Key Research and Development Program of China (Grant No. 2017YFC0404200), the Key Research and Development Program of Tianjin (Grant No. 18YFZCSF00310), the Key Laboratory of Fluid and Power Machinery (Xihua University) Ministry of Education (Grant No. SZJJ-2018-125).

Institutional Review Board Statement: Not applicable.

Informed Consent Statement: Not applicable.

Data Availability Statement: All the data is already in the article.

Conflicts of Interest: The authors declare no conflict of interest.

\section{References}

1. Kim, J.; Lee, H.; Yoon, J.; Lee, K.; Lee, Y.; Choi, Y. Multi Objective Optimization of a Multiphase Pump for Offshore Plants. In Proceedings of the ASME 2014 4th Joint Us-European Fluids Engineering Division Summer Meeting, Chicago, IL, USA, 3-7 August 2014.

2. Suh, J.; Kim, J.; Choi, Y. Development of numerical Eulerian-Eulerian models for simulating multiphase pumps. J. Pet. Sci. Eng. 2018, 162, 588-601. [CrossRef]

3. Zhang, J.; Zhu, H.; Yang, C.; Li, Y.; Wei, H. Multi-objective shape optimization of helico-axial multiphase pump impeller based on NSGA-II and ANN. Energy Convers. Manag. 2011, 52, 538-546. [CrossRef]

4. Zhang, J.; Cai, S.; Li, Y.; Zhu, H.; Zhang, Y. Visualization study of gas-liquid two-phase flow patterns inside a three-stage rotodynamic multiphase pump. Exp. Therm. Fluid Sci. 2016, 70, 125-138. [CrossRef]

5. Zhang, J.; Cai, S.; Zhu, H.; Zhang, Y. Experimental investigation of the flow at the entrance of a rotodynamic multiphase pump by visualization. J. Pet. Sci. Eng. 2015, 126, 254-261. [CrossRef]

6. Suh, J.; Kim, J.; Choi, Y.; Kim, J.; Joo, W.; Lee, K. Multi-Objective Optimization of the Hydrodynamic Performance of the Second Stage of a Multi-Phase Pump. Energies 2017, 10, 1334. [CrossRef]

7. Kim, J.; Lee, H.; Kim, J.; Choi, Y.; Yoon, J.; Yoo, I.; Choi, W. Improvement of Hydrodynamic Performance of a Multiphase Pump Using Design of Experiment Techniques. J. Fluids Eng. 2015, 137, 081301. [CrossRef]

8. Tan, L.; Xie, Z.; Liu, Y.; Hao, Y.; Xu, Y. Influence of T-shape tip clearance on performance of a mixed-flow pump. Proc. Inst. Mech. Eng. Part A J. Power Energy 2018, 232, 386-396.

9. Liu, Y.; Tan, L. Spatial-Temporal Evolution of Tip Leakage Vortex in a Mixed-Flow Pump with Tip Clearance. ASME J. Fluids Eng. 2019, 141, 081302. [CrossRef]

10. Liu, Y.; Han, Y.; Tan, L.; Wang, Y. Blade rotation angle on energy performance and tip leakage vortex in a mixed flow pump as turbine at pump mode. Energy 2020, 206, 118084. [CrossRef]

11. Liu, Y.; Tan, L. Theoretical Prediction Model of Tip Leakage Vortex in a Mixed Flow Pump with Tip Clearance. ASME J. Fluids Eng. 2020, 142, 021203. [CrossRef]

12. Wu, H.; Tan, D.; Miorini, R.; Katz, J. Three-dimensional flow structures and associated turbulence in the tip region of a waterjet pump rotor blade. Exp. Fluids 2011, 51, 1721-1737. [CrossRef]

13. Wu, H.; Miorini, R.; Katz, J. Measurements of the tip leakage vortex structures and turbulence in the meridional plane of an axial water-jet pump. Exp. Fluids 2011, 50, 989-1003. [CrossRef] 
14. Miorini, R.; Wu, H.; Katz, J. The Internal Structure of the Tip Leakage Vortex Within the Rotor of an Axial Waterjet Pump. ASME J. Turbomach. 2012, 134, 1-12. [CrossRef]

15. Peng, X.; Xu, L.; Liu, Y.; Zhang, G.; Cao, Y.; Hong, F.; Yon, K. Experimental measurement of tip vortex flow field with/without cavitation in an elliptic hydrofoil. J. Hydrodyn. 2017, 29, 939-953. [CrossRef]

16. Shen, X.; Zhang, D.; Xu, B.; Jin, Y.; Shi, W.; van Esch, B. Experimental Investigation of the Transient Patterns and Pressure Evolution of Tip Leakage Vortex and Induced-Vortices Cavitation in an Axial Flow Pump. ASME J. Fluids Eng. 2020, $142,1-11$.

17. Zhang, J.; Fan, H.; Zhang, W.; Xie, Z. Energy performance and flow characteristics of a multiphase pump with different tip clearance sizes. Adv. Mech. Eng. 2019, 11,1-14. [CrossRef]

18. Zhang, J.; Tan, L. Energy Performance and Pressure Fluctuation of a Multiphase Pump with Different Gas Volume Fractions. Energies 2018, 11, 1216. [CrossRef]

19. Shi, G.; Liu, Z.; Xiao, Y.; Yang, H.; Li, H.; Liu, X. Effect of the inlet gas void fraction on the tip leakage vortex in a multiphase pump. Renew. Energy 2020, 150, 46-57. [CrossRef]

20. Shi, G.; Liu, Z.; Xiao, Y.; Li, H.; Liu, X. Tip leakage vortex trajectory and dynamics in a multiphase pump at off-design condition. Renew. Energy 2020, 150, 703-711. [CrossRef]

21. Zhang, D.; Shi, W.; van Esch, B.; Shi, L.; Dubuissonb, M. Numerical and experimental investigation of tip leakage vortex trajectory and dynamics in an axial flow pump. Comput. Fluids 2015, 112, 61-71. [CrossRef]

22. Zhang, D.; Shi, L.; Shi, W.; Zhao, R.; Wang, H.; van Esch, B. Numerical analysis of unsteady tip leakage vortex cavitation cloud and unstable suction-side-perpendicular cavitating vortices in an axial flow pump. Int. J. Multiph. Flow 2015, 77, 244-259. [CrossRef]

23. Shen, S.; Qian, Z.; Ji, B.; Agarwal, R. Numerical investigation of tip flow dynamics and main flow characteristics with varying tip clearance widths for an axial-flow pump. Proc. Inst. Mech. Eng. Part A J. Power Energy 2019, 233, 476-488. [CrossRef]

24. Feng, J.; Luo, X.; Guo, P.; Wu, G. Influence of tip clearance on pressure fluctuations in an axial flow pump. J. Mech. Sci. Technol. 2016, 30, 1603-1610. [CrossRef]

25. Yu, Z.; Zhang, W.; Zhu, B.; Li, Y. Numerical analysis for the effect of tip clearance in a low specific speed mixed-flow pump. Adv. Mech. Eng. 2019, 11, 1-12. [CrossRef]

26. Zhang, W.; Yu, Z.; Zhu, B. Influence of Tip Clearance on Pressure Fluctuation in Low Specific Speed Mixed-Flow Pump Passage. Energies 2017, 10, 148. [CrossRef]

27. Wang, L.; Lu, J.; Liao, W.; Zhao, Y.; Wang, W. Numerical Simulation of the Tip Leakage Vortex Characteristics in a Semi-Open Centrifugal Pump. Appl. Sci. 2019, 9, 5244. [CrossRef]

28. Zhang, C.; Dong, X.; Liu, X.; Gao, Q.; Tan, C.; Zeng, D. One-dimensional modeling for tip clearance leakage vortex trajectory and stall-onset prediction in subsonic centrifugal impellers. Proc. Inst. Mech. Eng. Part A J. Power Energy 2020, 234, 263-282. [CrossRef]

29. Galindo, J.; Tiseira, A.; Navarro, R.; Lopez, M. Influence of tip clearance on flow behavior and noise generation of centrifugal compressors in near-surge conditions. Int. J. Heat Fluid Flow 2015, 52, 129-139. [CrossRef]

30. Borello, D.; Hanjalic, K.; Rispoli, F. Computation of tip-leakage flow in a linear compressor cascade with a second-moment turbulence closure. Int. J. Heat Fluid Flow 2007, 28, 587-601. [CrossRef]

31. Park, K.; Choi, H.; Choi, S.; Sa, Y. Effect of a casing fence on the tip-leakage flow of an axial flow fan. Int. J. Heat Fluid Flow 2019, 77, 157-170. [CrossRef]

32. Jung, J.; Joo, W. Effect of tip clearance, winglets, and shroud height on the tip leakage in axial flow fans. Int. J. Refrig. 2018, 93, 195-204. [CrossRef] 